\title{
Experimental investigations on the load-bearing behaviour of an innovative prestressed composite floor system in fire
}

\author{
P. Schaumann ${ }^{a}$, P. Meyer ${ }^{a *}$, M. Mensinger ${ }^{b}$ and S. K. Koh ${ }^{b}$ \\ ${ }^{a}$ Institute for Steel Construction, Leibniz University Hannover, Germany \\ ${ }^{b}$ Chair of Metal Structures, Technical University of Munich, Germany \\ *corresponding author, e-mail address: meyer@stahl.uni-hannover.de
}

\begin{abstract}
In Germany, regulations for hollow spaces in slab systems require 30 minutes standard fire resistance of the load-bearing steel construction. Within a current national research project a natural fire scenario for the hollow space was developed based on realistic fire loads and ventilation conditions in the hollow space. Assuming this realistic fire scenario in the hollow space, two large scale tests on an innovative composite floor system were performed to evaluate the influence on the load bearing behaviour of the floor system.

The integrated and sustainable composite floor system consists of a prestressed concrete slab, an unprotected, bisected hot rolled I-profile with composite dowels either in puzzle or clothoidal shape, and removable floor panels on the top of the I-profile. This floor system ensures the opportunity to adjust the technical building installations in accordance with the use of the building. This integrated and sustainable composite floor system was developed in several research projects. The standard fire resistance R90 for the fire scenario below the slab system has already been proven successfully.

In this paper, experimental investigations regarding the heating and load bearing behaviour of the innovative composite floor system under the newly developed natural fire scenario of hollow spaces are presented. In doing so, the special test set-up to realise the fire tests for the fire scenario hollow space will be described in detail. After the fire scenario for the hollow space, the specimen was subjected to the ISO standard fire curve to establish the failure temperature of the unprotected I-profile. In addition to the temperature development and the load bearing behaviour inside the innovative floor during the heating phase, the cooling phase and the influence of a web opening on the load bearing behaviour will be discussed.
\end{abstract}

Keywords: innovative composite floor system; natural fire scenario; load-bearing behaviour; thermal behaviour in cooling and heating phase

\section{Introduction}

At the present time, the importance of a resource-saving and sustainable construction receives a significant part in the design stage of a structure because of regulations for climate protection. Therefore in several research projects [5], an integrated and sustainable composite floor system was developed considering of a high flexibility and adaptability of the usage over the entire life cycle of the building without affecting the load-bearing structure. The integrated and sustainable composite floor system (so- called InaDeck) consists of a prestressed concrete slab, an unprotected, bisected hot rolled Iprofile with composite dowels either in puzzle or clothoidal shape, and removable floor panels on the top of the I-profile (see Fig. 1).

The removable floor panels form a hollow space between the concrete slab and the flanges of the I-profiles and enable the opportunity to adjust the technical building installations in accordance with the use of the building. The web openings of the hot rolled I-profile ensure an adaptable usage for a changing installation of the building as well. 


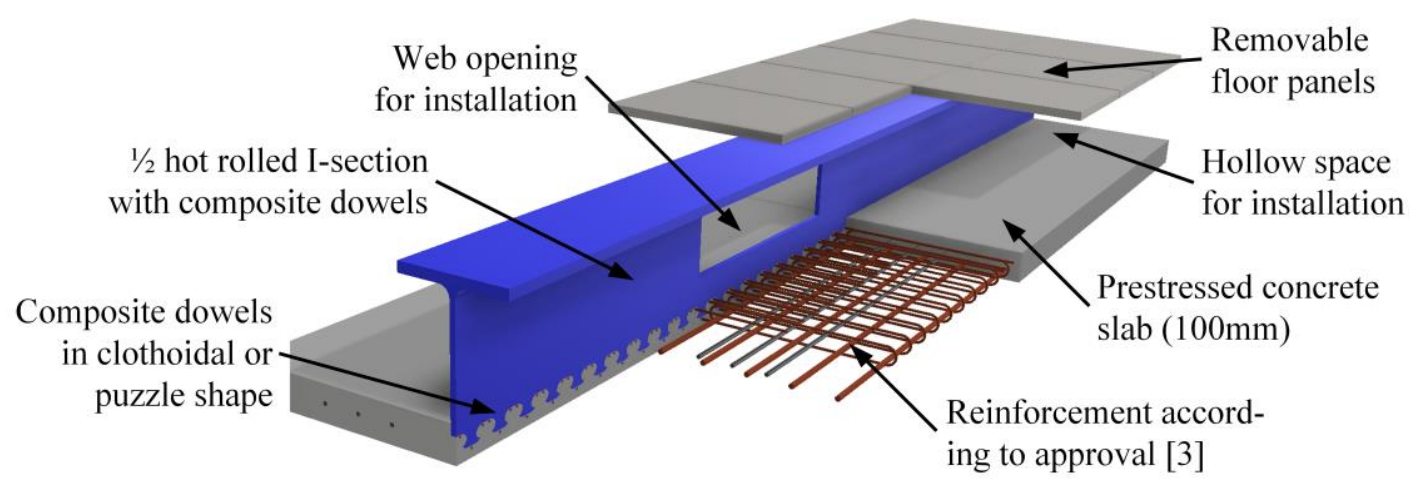

Fig. 1. Overview of the innovative composite floor system InaDeck.

The integrated and sustainable composite floor system InaDeck was developed as a precast system for systems length up to $16 \mathrm{~m}$ with a slender prestressed concrete slab, a live load of $5 \mathrm{kN} / \mathrm{m}^{2}$, and for the usage in multi storey buildings. As shear connectors composite dowels either in puzzle or clothoidal shaped are used according to the German approval [3]. Composite dowels are recently developed shear connectors to build innovative composite structures. The standard fire resistance of 90 minutes (R90) for the fire scenario below the integrated and sustainable composite floor system has already been proven successfully [5],[6]. Besides the requirements for the fire scenario below slab systems as well as regulations for the hollow space are necessary to consider. In Germany, these regulations for the hollow spaces in slab systems require a minimum of 30 minutes standard fire resistance of the load-bearing steel construction (R30) [1], [2]. In doing so, the steel construction of a composite beam requires external fire protection. Consequently, composite slab systems are uneconomic in comparison to other slab systems because of the necessary fire protection of the I-profile.

However, the fire loads and ventilation conditions in the hollow space may be not sufficient enough to reach temperatures comparable to the ISO standard fire curve. Therefore, in a current national research project a natural fire scenario for the hollow space was developed based on realistic fire loads and ventilation conditions in the hollow space [7], [8]. Assuming this realistic fire scenario in the hollow space, two large-scale tests on the system InaDeck were performed to investigate the load-bearing behaviour.

In this paper, the experimental investigations on the system InaDeck will be presented. Throughout the heating phase, the specimens were subjected to the fire scenario for hollow space and the ISO standard fire curve. Besides the load-bearing behaviour of the slab system, the influence of the web opening on the loadbearing behaviour and the cooling phase of the materials will be discussed.

\section{Experimental investigations}

\subsection{Fire scenario "hollow space"}

As aforementioned, it has to be investigated what fire scenario is appropriate for the real fire loads in the hollow space, which consists mainly of electric cables [7], [8]. To develop this specific fire curve, a number of small-scale tests were performed, on which basis a simplified fire scenario for the hollow space was derived (see Fig. 2). The fire scenario hollow space covers the $95 \%$ fractile value of all fire tests. Characterising for the simplified curve of the fire scenario hollow space are three significant branches. The first branch is the linear increase of the temperature up to $500{ }^{\circ} \mathrm{C}$ within 5 minutes. Second is the constant temperature level of $500{ }^{\circ} \mathrm{C}$ for 10 minutes after the linear development of the temperature. The last part of the simplified curve is an exponential decrease of the temperature until the temperature reaches the room temperature again.

As an approximation of the simplified curve for the furnace temperature of the fire tests, the descending branch of the temperature was estimated linearly. Moreover, after the fire scenario hollow space the specimens were subjected to the ISO standard fire curve until the failure of the composite slab system. The ISO standard fire curve was started in the cooling phase after 25 minutes. Based on the assumption that at this stage the specimen overcomes the fire scenario hollow space. 


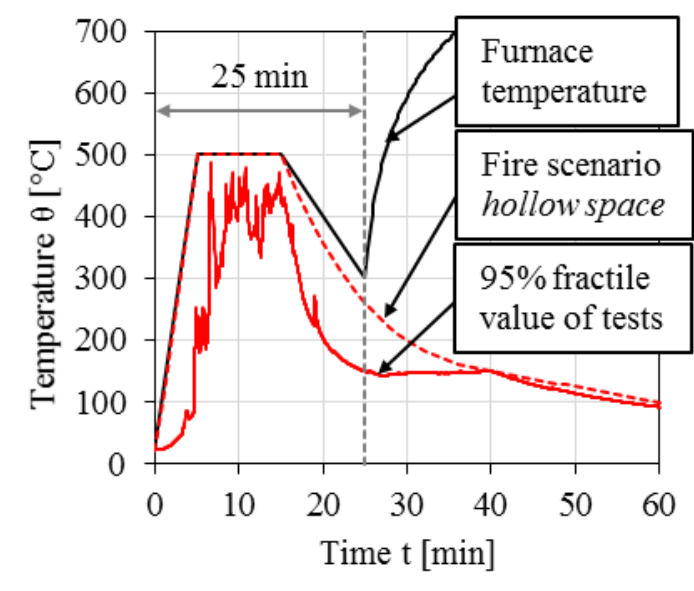

Fig. 2. Temperatures versus time curves of fire scenario for hollow spaces and the furnace temperature.

\subsection{Structure of the test specimens}

The load-bearing behaviour of the two specimens each with a length of $7.8 \mathrm{~m}$ and one specimen with a web opening were investigated in the fire scenario hollow space. The specimens consist of a bisected HE800A with composite dowels in clothoidal shape with a longitudinal distance $e_{x}$ of $100 \mathrm{~mm}$ according to the German approval [3] and a prestressed concrete slab with a width of $1.25 \mathrm{~m}$ and a thickness of $100 \mathrm{~mm}$ (see Fig. 3). Moreover, the influence of a web opening of $750 \mathrm{~mm} \times 250 \mathrm{~mm}$ for installation in the transverse direction on the load bearing behaviour during the fire scenario hollow space was taken into account. The web opening was positioned typically at the side of the slab systems with a distance of $1025 \mathrm{~mm}$ from the edge of the specimen (see Fig. 4).

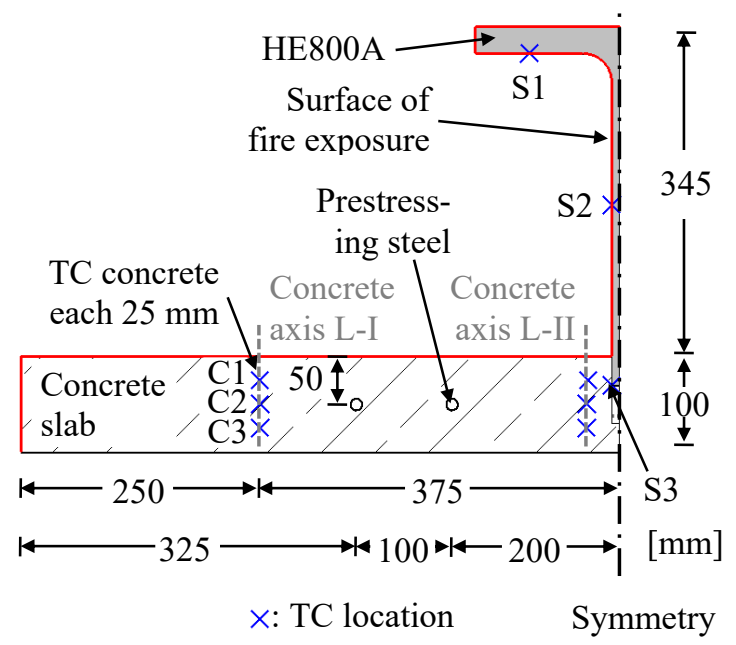

Fig. 3. Cross-section of the specimens.

To realise system length up to $16 \mathrm{~m}$ the concrete slab of the system InaDeck is prestressed.
On the basis of previous project [5], the specimens were prestressed according to the selfweight gk (including the removable floor panels) and the live load of $2.5 \mathrm{kN} / \mathrm{m}^{2}$. In doing so, the value of prestress of each prestressing steel amounts $\sigma_{\text {pmo }} 1075 \mathrm{~N} / \mathrm{mm}^{2}$. To realise the prestressing of the concrete slab four prestressing steels with a diameter of $12.5 \mathrm{~mm}$ are utilised. On the basis of the design of the slab system, the diameter of the longitudinal reinforcement was chosen as $16 \mathrm{~mm}$ and the diameter of the upper reinforcement and concrete reinforcement of the composite dowels were chosen as $8 \mathrm{~mm}$. The arrangement of the reinforcement of the composite dowels corresponds to the German approval [3] (see Fig. 5).

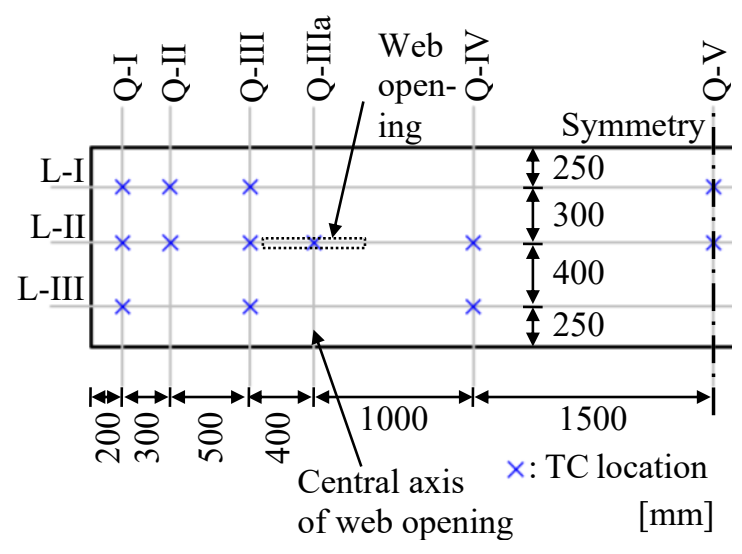

Fig. 4. View of positions of thermocouples in longitudinal and transversal direction.

The temperature during the fire tests are measured with thermocouples (TC) of type K and are assembled at the I-profile and in the concrete slab of the floor system. The temperature of the bisected HE800A was measured at the flange (S1), in the middle of the web (S2), and at the beginning of the composite dowel (S3) (see Fig. 3). To evaluate the influence on the heating behaviour of the web opening two extra $\mathrm{TC}$ at the web opening were applied; one TC above and one beneath the web opening. The temperatures in the concrete slab were measured every $25 \mathrm{~mm}$ in the concrete slab (see Fig. 5). Besides the temperature distribution through the height the temperature field in longitudinal and transversal direction was recorded (see Fig. 4).

Furthermore, the material properties of each part of the specimens were determined (see Table 1). The cube compressive strength of the concrete was determined after 28 days and as well on the date of the fire test to obtain the concrete material properties and to evaluate increase in the compressive strength over the time. 


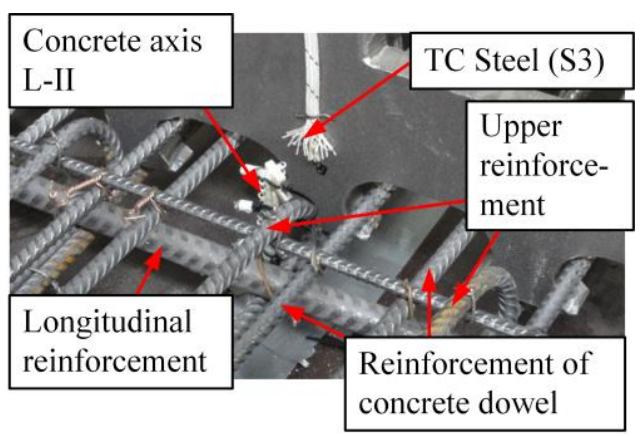

Fig. 5. Reinforcement of composite dowels of the specimens and temperature measuring points in the concrete and at the steel (I-profile).

Table 1. Material properties of the different parts of the cross-section.

\begin{tabular}{|c|c|}
\hline Material & Measured values \\
\hline $\begin{array}{l}\text { Steel } \\
\text { S355 }\end{array}$ & $\begin{array}{c}\mathrm{f}_{\mathrm{a}, \mathrm{y}}=446 \mathrm{~N} / \mathrm{mm}^{2} \\
\mathrm{f}_{\mathrm{a}, \mathrm{u}}=546 \mathrm{~N} / \mathrm{mm}^{2} \\
\mathrm{E}_{\mathrm{a}}=210,000 \mathrm{~N} / \mathrm{mm}^{2}\end{array}$ \\
\hline $\begin{array}{c}\text { Concrete } \\
\text { C50/60 }\end{array}$ & $\begin{array}{c}\mathrm{f}_{\mathrm{c}, \text { cube }, \mathrm{m}}(28 \mathrm{~d})=75.5 \mathrm{~N} / \mathrm{mm}^{2} * \\
\mathrm{f}_{\mathrm{c}, \text { cube,m }}(113 \mathrm{~d})=77.4 \mathrm{~N} / \mathrm{mm}^{2} * * \\
\mathrm{f}_{\mathrm{c}, \text { cyl,m }}(28 \mathrm{~d})=70,4 \mathrm{~N} / \mathrm{mm}^{2} * \\
\mathrm{E}(28 \mathrm{~d})=45,500 \mathrm{~N} / \mathrm{mm}^{2} *\end{array}$ \\
\hline $\begin{array}{c}\text { Reinforce- } \\
\text { ment } \\
\mathrm{BSt} 500 \\
(\varnothing 8, \varnothing 16)\end{array}$ & $\begin{array}{c}\mathrm{f}_{\mathrm{s}, 0,2, \mathrm{k}, \mathrm{m}}=551 \mathrm{~N} / \mathrm{mm}^{2} * \\
\mathrm{f}_{\mathrm{s}, \mathrm{t}, \mathrm{m}}=648 \mathrm{~N} / \mathrm{mm}^{2} * \\
\mathrm{E}_{\mathrm{s}, \mathrm{m}}=202,412 \mathrm{~N} / \mathrm{mm}^{2} *\end{array}$ \\
\hline $\begin{array}{l}\text { Prestressing } \\
\text { steel } \\
\text { St1660/1860 } \\
(\varnothing 12.5)\end{array}$ & $\begin{array}{c}\mathrm{f}_{\mathrm{p}, 0,2, \mathrm{k}}=1660 \mathrm{~N} / \mathrm{mm}^{2} \\
\mathrm{f}_{\mathrm{p}, \mathrm{t}}=1860 \mathrm{~N} / \mathrm{mm}^{2} \\
\mathrm{E}_{\mathrm{p}}=196,000 \mathrm{~N} / \mathrm{mm}^{2}\end{array}$ \\
\hline
\end{tabular}

* Mean value of 3 specimens

** Determination on date of fire test

\subsection{Test set-up and procedure}

In the assembly situation, the system InaDeck is usually integrated with the concrete slab in the tension zone of the cross-section (see Fig. 1). The load-bearing behaviour would be established within a fire test by a four-point bending test (see Fig. 6(a)). In consideration of the boundary conditions and limitation of the displacement of the test facility (furnace), there is no opportunity to enable the fire scenario hollow space in the usual assembly situation of the floor system. Therefore, a special test set-up was developed to realise the fire test for the natural fire scenario. In this special test set-up the assembly situation of the specimens is modified. In doing so, the specimens are rotated along the longitudinal axis so that the concrete slab is at the top of the cross

section (see Fig. 6(b)). Instead of loading the specimens in the third points following the procedure of a four-point bending test, the specimens are loaded at both ends and fixed in the third points of the specimen (see Fig. 6(b)). Nevertheless, the same stress behaviour of the rotated specimen is realised due to the adjusted loading situation and adjusted boundary conditions. Despite the change in the statical system, the thermal expansion of the specimen is not impeded.

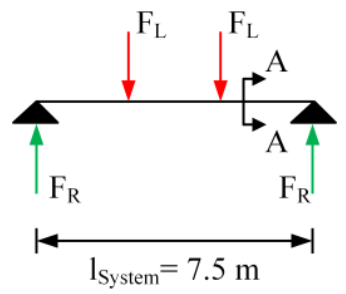

Section:

A-A

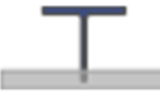

Fig. 6(a). Statical system of four-point bending (normal Situation).

\section{Fig. 6. Comparison of different statical sys- tems of test set-up for the fire test.}

Besides the measurement of temperature over time, the displacements of the specimens are measured at the load introduction and in the middle of the specimens (see Fig. 7). To assess a possible bending along the longitudinal axis of the specimens at each measuring axis two measuring points are installed with a distance of $250 \mathrm{~mm}$ to the edge of the specimen. The displacements in the fire test are measured with potentiometers.
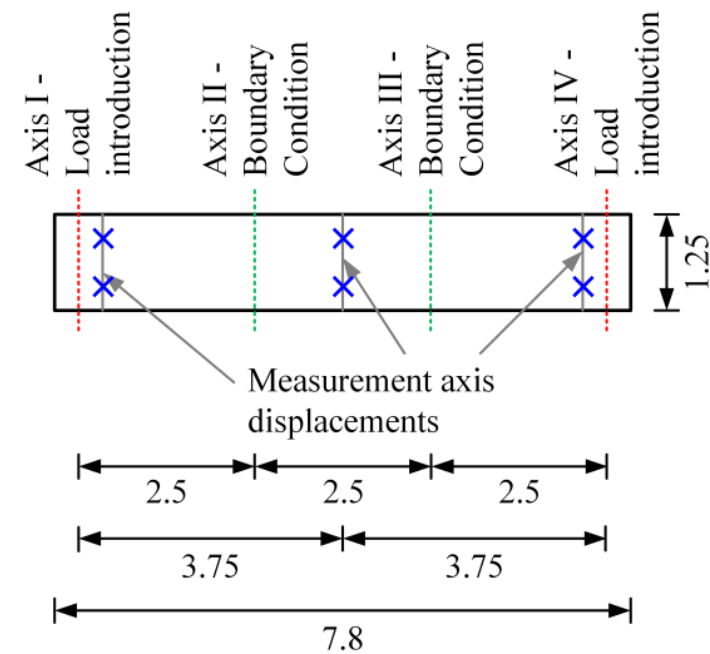

Fig. 7. Overview of the axis of the boundary conditions and measurement points of displacements. 
To realise the boundary conditions of the special test set-up the specimens are suspended with a steel construction in the furnace (see Fig. 8). The suspension of the specimen in axis II and III is realised by a steel construction consisting of HE180B I-profiles. The connection between the suspending construction and the specimen is ensured by a bolted connection. Therefore, steel plates are welded to the web and the flange of the I-profile.

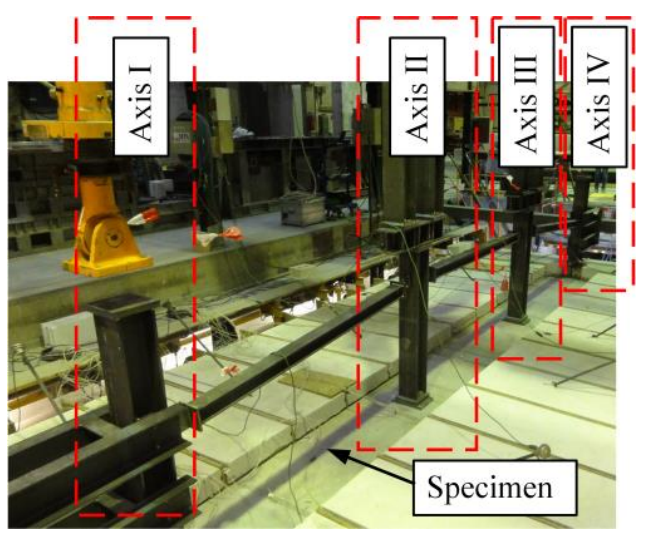

Fig. 8. Test set-up of the fire test.

In the fire test, the loading of the specimen followed the procedure according to DIN EN 1363-1 [4]. The load applied is derived on the basis of the utilisation factor of the floor system with a length of $16 \mathrm{~m}$. The utilisation factor of the specimens in the fire tests with a length of 7.5 $\mathrm{m}\left(\eta_{7.5 \mathrm{~m}}\right)$ is equal to the utilisation factor of the $16 \mathrm{~m}$ system $\left(\eta_{16 \mathrm{~m}}\right)$ of $29.5 \%$. During the fire test, the applied loads on the specimens are kept constant over the time. In the fire test, the specimen is subjected to the natural fire scenario hollow space followed by the ISO standard curve.

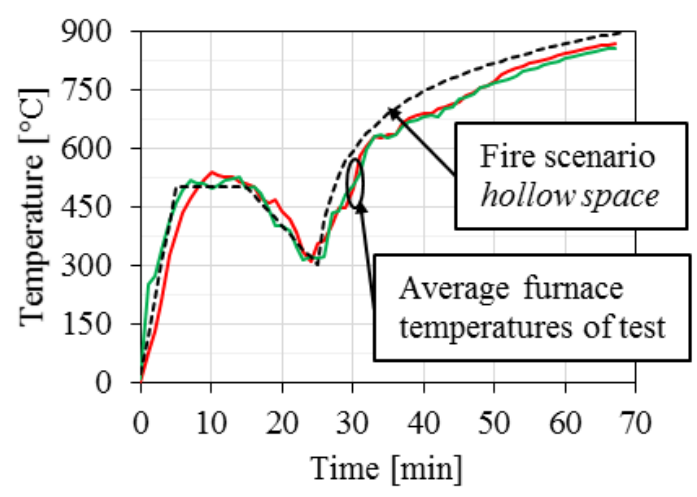

Fig. 9. Comparison of the designated and measured temperature versus time curves of the furnace.

The ISO standard fire curve is applied after 25 minutes of the fire scenario hollow space. This implies that once the fire scenario hollow space is not critical for the load bearing behaviour of the floor system the failure temperature of the floor system is determined under standard fire conditions. The designated temperature versus time curve of the fire impact and the average temperature time curves of the measured furnace temperatures are shown in Fig. 9.

\section{Results}

\subsection{Thermal behaviour of specimen}

The temperatures of the steel section and the concrete slab of the specimens are measured during the heating and the cooling phase. The average temperature time curves of the steel section of the specimens during the heating phase are shown in Fig. 10. The temperature evaluation of the specimens are almost identical. During the natural fire scenario hollow space, the temperature of the flange of the I-profile is only reaching approximately $350{ }^{\circ} \mathrm{C}$. Once the specimen is subjected to the ISO fire curve, the temperature in the steel section of the specimens are rising continuously. The steel temperatures are rising until failure of the system occurs. At this stage, the part of the I-profile directly exposed to the fire impact has a temperature of approximately $800^{\circ} \mathrm{C}$. This temperature can be designated as failure temperature of the system.

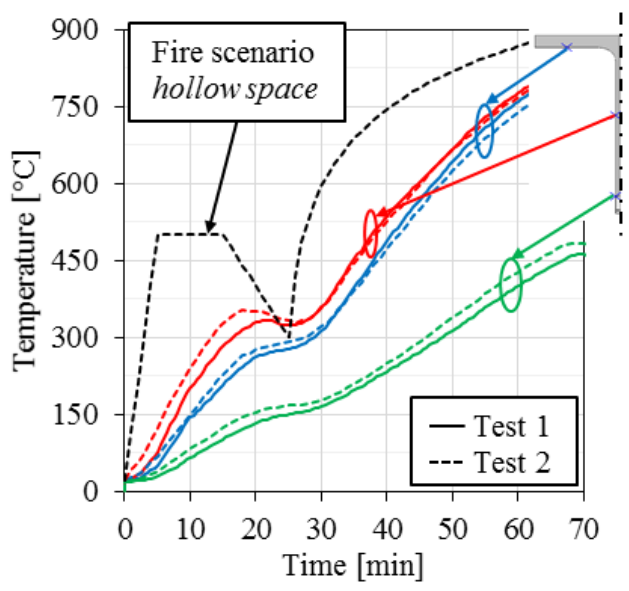

Fig. 10. Average temperature versus time curves of the I-profile in the heating phase.

Furthermore, the temperatures distribution of the concrete slab during the heating phase are shown in Fig. 11. Within the fire scenario hollow space, the temperatures in the concrete slab are only reaching values of approximately $140{ }^{\circ} \mathrm{C}$ at the fire exposed surfaces. The temperature in the concrete slab is decreasing with increasing distance to the fire exposed surface. A decrease or a plateau in the temperature evaluation similar to 
the steel section after 15 minutes is not noticeable in the concrete slab. Equally to the temperatures in the steel section of the specimen, the temperatures in the concrete slab are increasing once the specimen is subjected to the ISO standard fire curve (see Fig. 11). As aforementioned the temperatures in the concrete slab are measured in three axes (L-I, L-II, L-III, see Fig. 3 and Fig. 4). The position of the measuring axis (L-II) is in the shear joint of the specimen (see Fig. 3). The temperatures in the concrete slab in the shear joint of the specimen are reaching maximum temperatures of approximately $400{ }^{\circ} \mathrm{C}$. The temperatures in axis L-II are correlating with the measured temperatures at the composite dowels of the I-profile (see Fig. 10). In comparison to this measuring axis L-II, the temperatures in the concrete slab (L-I) are only reaching values up to approximately $275^{\circ} \mathrm{C}$. The temperature in the concrete slab of the shear joint is influenced by the heat transfer of the I-profile. The evaporation of the pore water in the concrete slab is represented due to the plateau at approximately 25 to 40 minutes (see Fig. 11). The temperature distribution in the transversal direction of the specimen is constant. Therefore, the axis LI represents the axis L-III of the concrete slab.

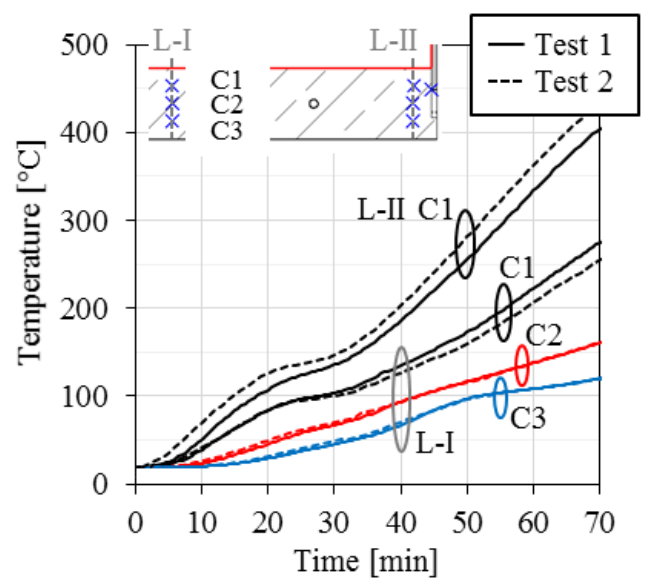

Fig. 11. Average temperature versus time curves of the concrete slab in the heating phase.

Besides the heating phase of the specimen, the temperatures are documented during the cooling phase of the specimen. The cooling behaviour of the steel and concrete are similar (see Fig. 12). During the cooling phase of the materials steel and concrete, the temperatures are dropping continuously. A plateau in the temperature versus time curves compared to the plateau caused by the evaporating of the pore water of the concrete is not noticeable in the cooling phase.

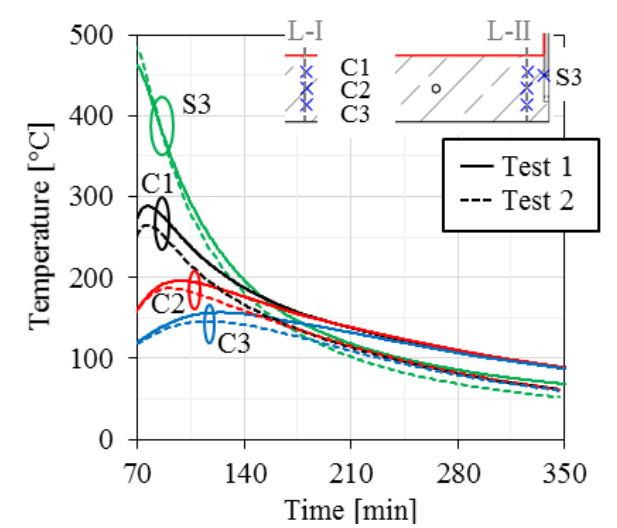

Fig. 12. Average temperature versus time curves of the steel and concrete in the cooling phase.

\subsection{Mechanical behaviour of slab system}

As aforementioned, the displacement of the specimens is measured at the load introductions and in the middle of the specimen. Moreover, the displacement is measured at points in the transversal direction to evaluate a possible influence of bending along the longitudinal axis of the specimen. Nevertheless, a bending along the longitudinal axis of the specimen is not observed. Also, the displacement behaviour of the load introduction axis I and IV (see Fig. 7) are similar and hence only one displacement curve is considered in the following. Once the load is applied on the specimen (without a web opening) a displacement of approximately $7.5 \mathrm{~mm} \mathrm{oc-}$ curred (Fig. 13).

Due to the direct exposure of the unprotected I-profile of the cross-section to the fire impact the I-profile heats up more rapidly compared to the concrete slab. On the basis of this, a significant temperature gradient occurs in the crosssection of the specimen. As a consequence of the thermal gradient in the cross-section, the thermal expansion of the I-profile is higher than the thermal expansion of the concrete slab. This results in a bending of the specimen towards the concrete slab. Based on the induced thermal expansion bending of the specimen, the specimen expands at the load introduction axis with a positive displacement in the z-axis (see Fig. 13). The resulting bending of the specimen due to the thermal expansion of the specimen decreases after reaching a critical temperature of approximately $700{ }^{\circ} \mathrm{C}$ in the I-profile. Once the maximum displacement of $70 \mathrm{~mm}$ caused by the resulting thermal bending of the specimen is reached, the displacement increases until failure due to bending occurs after 68 minutes. At this 
stage, a maximum displacement of approximately $125 \mathrm{~mm}$ occurs. The maximum displacement after the heating and cooling of the specimen without a web opening is approximately $275 \mathrm{~mm}$ relating to the $7.8 \mathrm{~m}$ system length.

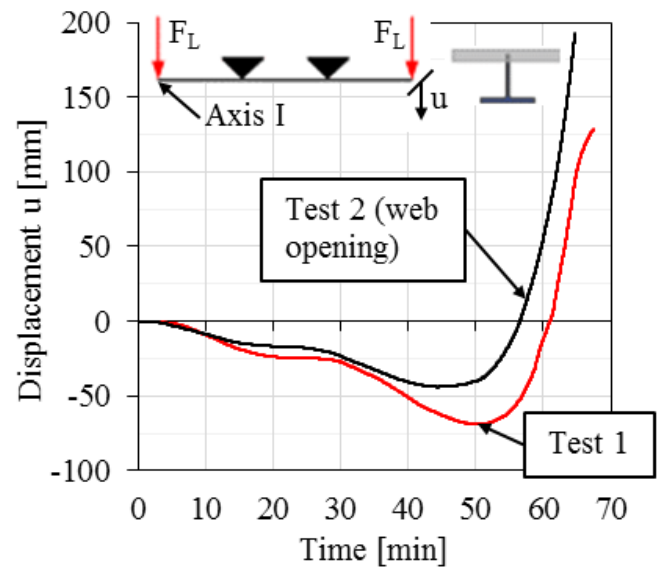

Fig. 13. Comparison of displacement behaviour of the specimen with and without a web opening at the load introduction axis I.

The displacement behaviour at the load introduction axis of the specimen with the web opening is considered separately. The behaviour of part of the specimen without the web opening performs similarly to the load bearing behaviour of the first specimen. Indeed, the part of the specimen with the web opening performs differently. Compared to the first specimen, the displacement of the part of the specimen with the web opening amounts approximately $14 \mathrm{~mm}$. This is approximately twice the magnitude of displacement compared to the part without a web opening. Over the time of the fire test, the loadbearing behaviour of the part with the web opening performs similarly to the system without a web opening. Due to the thermal expansion of the I-profile, the thermal induced bending of the specimen occurs as well. Certainly, the displacement of the part without a web opening is only half of the magnitude of the specimen with the web opening (see Fig. 13). The thermal induced bending of the specimen with the web opening leads to a maximum expansion of the specimen in the vertical direction of approximately $35 \mathrm{~mm}$. This value is half the magnitude of the vertical displacement of the specimen without a web opening and is correlating to the performance of the specimen once the load is applied. Nevertheless, the maximum value of the induced thermal bending displacement in vertical direction occurs at an earlier stage compared to the specimen without a web opening. The difference between the maximum values of the vertical displacement is 5 minutes. The difference in the load-bearing behaviour of the specimens with and without a web opening is caused by the reduced stiffness of the web.

\subsection{Results of fire tests}

The fire test with the natural fire scenario hollow space proves that the realistic fire scenario in the hollow space is not endangering to influence the composite floor system in such a way that failure occurs. As a result of the fire test, additional fire protection of the I-profile is not necessary whereas the newly developed natural fire scenario is applied. Moreover, the fire tests indicate that even 30 minutes standard fire resistance can be reached without any fire protection of the I-Profile before failure of the composite system occurs.

The floor system failed in both cases due to a bending failure. Nevertheless, the failure of the second specimen is dominated by the load-bearing behaviour of the web opening. Although the I-profile of the specimen is in the compression zone of the composite floor system, a buckling of the web is not observed in the fire tests. Moreover, no spalling effects of the concrete occur in the fire tests despite temperatures of $850{ }^{\circ} \mathrm{C}$ are reached in the furnace.

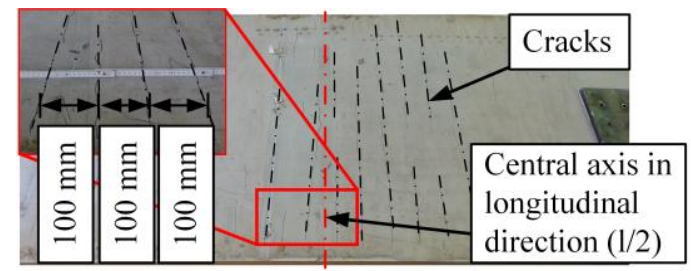

Fig. 14. Regular transversal crack pattern in longitudinal direction on the top of the concrete slab.

On the top side of the specimens, a regular crack pattern occurred. The crack pattern occurred in the bended part of the concrete. The cracks occur with a regular distance of $100 \mathrm{~mm}$ (see Fig. 14). The cracks appear adjacent to the composite dowels in the longitudinal direction of the specimen. As aforementioned, the second specimen was dominated by the failure of the web opening. At the web opening, the "Vierendeel effect" occurs and the local displacement behaviour of the web opening is opposite to the global displacement behaviour of the specimen. Due to the Vierendeel effect, the composite dowel on the side of the web opening orientating 
to the middle is pressed into the concrete slab (see Fig. 15).

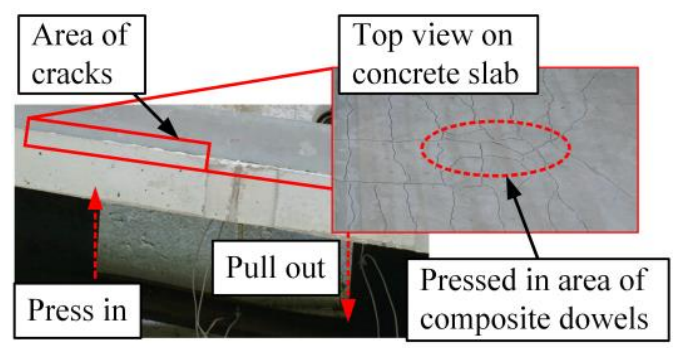

Fig. 15. Displacement of web opening and crack pattern caused by the pressed in composite dowel on top of the concrete slab.

\section{Conclusion and Outlook}

In this paper, a special test set-up for evaluating of the load bearing behaviour of a floor system in consideration of a newly developed natural fire scenario for hollow spaces is presented. Based on the natural fire scenario hollow space, two fire tests with the innovative composite floor system InaDeck are performed to investigate the load-bearing behaviour. Moreover, the influence of a web opening on the load bearing behaviour is investigated in the fire test. The fire tests prove that a fire protection of the I-profile of the composite floor system is not necessary to overcome the fire scenario hollow space. Moreover, a critical failure temperature during the fire scenario hollow space is not reached. Once the specimen is subjected to the ISO standard fire curve after the fire scenario for hollow spaces the system failed after approximately 32 minutes of exposure to the ISO standard fire curve. In fact, the composite floor system with the unprotected Iprofile is able to fulfil the fire resistance of 30 minutes. Furthermore, the temperatures in the cooling phase of the floor system are measured. The materials steel and concrete showed an exponential decrease in temperature during the cooling phase.

Based on this experimental investigations a numerical model will be developed and validated against the test data to evaluate the loadbearing behaviour more in detail. Moreover, studies on the web opening (size, position), utilisation factor will be performed for a detailed understanding of the behaviour of the innovative composite floor system InaDeck.

\section{Acknowledgements}

This IGF project (IGF-Nr. 18894N) of the FOSTA is supported via AiF within the programme for promoting the Industrial Collective Research (IGF) of the German Ministry of Economic Affairs and Energy (BMWi), based on a resolution of the German Parliament.

\section{References}

[1] Fachkommission Bauaufsicht der ARGEBAU, MBO Musterbauverordnung für die Länder der Bundesrepublik Deutschland, Fassung 11.2002 Central a(zuletzt geändert 09.2012). (in German)

[2] Fachkommission Bauaufsicht der ARGEBAU, Muster-Richtlinie über brandschutztechnische Anforderungen an Systemböden (MusterSystembödenrichtlinie (MSysBöR)), Fassung September 2005. (in German)

[3] Allgemeine bauaufsichtliche Zulassung Nr. Z-26.4-56, Verbunddübelleisten, Deutsches Institut für Bautechnik, 2013. (in German)

[4] DIN EN 1363-1: Fire resistance test - Part 1: General Requirements. German Version EN 1363-1: 2012, Oktober 2012.

[5] Hegger J, Claßen M, Gallwoszus J, Feldmann M, Pyschny D, Doering B, Schaumann P, Sothmann J, Weisheim W, Bohne D, Hargus S. Integrated and Sustainable Floor Slab Systems in Steel and Composite Structures, Research Project P 879, FOSTA, 2016.

[6] Hegger J, Claßen M, Gallwoszus J, Schaumann P, Weisheim W, Sothmann J, Feldmann M, Pyschny D, Bohne D, Hargus, S. Multifunctional composite slab system with integrated building services - Studies on the load bearing and fire behavior, thermal efficiency and sustainability of a novel composite floor system, Stahlbau 83 (7), p. 452 - 460, 2014.

[7] Mensinger M, Koh SK, Schaumann P, Meyer P. Rise of temperature in hollow spaces of suspended ceilings, in hollow space floors and access floors and its effects on the load-bearing capacity of inner steel elements, Research Project $P$ 1139, FOSTA, 2017 (current research project).

[8] Koh SK, Mensinger M, Meyer P, Schaumann P. Fire in hollow spaces: Short circut as ignition source and the role of ventilation, $2^{\text {nd }}$ International Fire safety Symposium (IFireSS) Naples, Italy, $7^{\text {th }}-9^{\text {th }}$ June, 2017. 